\title{
Loppumaton kamppailu: Laclaun anti-essentialistinen tulkinta identiteeteistä ja demokratiasta
}

Tämä saateteksti on kirjoitettu pohjustukseksi Politiikka-lehden numerossa 62:2 julkaistulle Ernesto Laclaun artikkelin "Universalismi ja partikularismi: kysymys identiteetistä?" suomennokselle (alkup. Laclau 1992). Laclaun artikkelin ovat suomentaneet Emilia Palonen ja Jouni Tilli. Suomennoksessa on käytetty Laclaun Emancipation(s)-kirjan revisoitua versiota loppukaneetteineen.

Tähän numeroon käännetyssä artikkelissaan ”Universalismi ja partikularismi: kysymys identiteetistä?" Ernesto Laclau korostaa yleisen ja erityisen paradoksista yhteenkietoutumista: kun samaistumme jonkin yksittäisen kanssa, siitä tulee yhteinen, mutta jokainen erillisyyttä korostava identiteettiväite hakee tunnustusta yleisemmältä tasolta. Artikkeli paljastaa niin erillistävien kuin yleistävien identiteettiväitteiden essentialismin ja yhteenliittyvyyden. Laclaun mukaan identiteetti on poliittinen kategoria, josta käytävä kamppailu on osa demokratiaa. Artikkeli käsittelee politiikkaa ja valtaa: samaistuminen on vallan prosessi ja politiikka luo samaistumisen kohteita. Tahdon avata artikkelia Politiikka-lehden lukijoille ja suomenkieliselle yleisölle, niin sisällön, tekstin merkityksen ja lyhyen kontekstoinnin kautta taustoituksen kautta.

Artikkeli kirjoitettiin 1990-luvun alussa, taustallaan uudet yhteiskunnalliset liikehdinnät ja muun muassa kylmän sodan ajan loppuminen. Essexin yliopiston professori Ernesto Laclau sekä hänen vaimonsa ja kanssateoreetikkonsa Chantal Mouffe olivat jo pitkään puhuneet uudenlaisen hegemoniakäsityksen puolesta. He olivat luoneet vaihtoehtoista kolmatta tietä identiteettipolitiikan aikakaudella, jolloin thatcherismi, apartheid ja Neuvostoliiton vaikutus rajoittivat demokratiaa. Radikaalidemokratia heille tarkoitti jatkuvaa vuoropuhelua vapauden ja tasa-arvon usein toisiaan poissulkevien vaatimusten välillä (ks. myös Palonen 2008). Laclaun mukaan essentialisointi on samanlaista, olipa kyseessä yleistä universaalisubjektia tai erillistä identiteettiä korostava prosessi. Vastauksena universaalisubjektin kuolemalle esiin nousivat moninaiset identiteetit ja identiteettipolitiikka. Myös nykyään "identiteettipolitiikasta" on tullut keskeinen termi: keskimääräisen äänestäjän tai intressien sijaan puolueet ovat alkaneet etsiä identiteettiryhmiä, joita edustaa. Laclau varoittaa, että tällainen prosessi vie ojasta allikkoon, koska ääripartikularismi eli eron korostaminen ja sen essentialisoiminen harvoin johtaa hyvään lopputulokseen. Loppumaton kamppailu, jossa "oikeaa vastausta" ei ole universalisoitu pysyvästi, on välttämätöntä niin tieteen kuin politiikan demokratialle.

Universaalisubjekti "me" syntyy konstituoivan eli perustavan artikulaation kautta. Siksi tätä lähestymistapaa on kutsuttu jälkiperustahakuiseksi (post-foundational), kuten Oliver Marchart (2007) luokitteli. Perustamisen prosessiluonne syntyy pohjimmiltaan anti-essentialismin vajeesta: "Meitä" ei ole olemassa ilman artikulaatiota ja samaistumista. Identiteetti ei ole valmis tai 
ennalta annettu käsite, vaikka poliittisessa prosessissa se usein essentialisoidaan ja kiinnitetään merkityksillä. Samaistumisen kohteet voivat olla ristiriitaisia tai tukea toisiaan. Niiden järjestys voi myös muuttua. Laclaun lähtökohta ottaa huomioon näiden yhteisöjen ja niiden tuottamien arvojen kontingenssin eli muutosalttiuden. Kontingenssi ei siis tässä traditiossa viittaa arpapeliin vaan merkitysten sisäänrakennettuun mahdollisuuteen tulla uudelleenartikuloiduksi kerta toisensa jälkeen. Uudelleenartikulaatio liittyy heiluriliikkeeseen essentialisoinnin ja positioinninmerkitysten kiinnittämisen välineiden ja politisoinnin eli merkitysten irrottamisen ja (uudelleen)kiinnittäminen välillä. Nämä ovat hyödyllisiäkin vallan työkaluja erilaisissa poliittisissa ja yhteiskunnallisissa kampailuissa. Politisointi on oikeastaan essentialismin vastakäsite: sen tehtävä on välttämättömistä tai olemuksellisista (lat. essentia, tarkoittaa olemusta, mutta huom. myös sen engl. johde essential) usein vakiintuneista merkityksistä irrottaminen.

Laclau väittää tekstinsä loppukaneeteissa, että demokratian tarkoitus on yleisen ja erityisen ratkaisemattomuus: on aina väitteitä erityisyydestä ja yleisyydestä. Tästä syntyy politiikan toimijoille ja yhteiskunnan demokratiaa ylläpitävä vuorovaikutus. Yhteiskunnan määritelmällinen avoimuus ei tarkoita sitä, että pääsemme yhteiseen neuvottelutulokseen emmekä myöskään pysyvään sotaan osapuolten välillä. Laclaun esimerkeissä äärimmäisen erityisyyden puolustajat tyrmäävät nykyisen järjestelmän ja sen poliittiset ja kulttuuriset arvot samaan aikaan artikuloiden sen olemassaolon itselleen esteeksi. Laclau torppaa ajatuksen, että olemassa erityisyyttä ilman yleisyyttä: jokainen erityisyysväite tehdään yleisyysväitteen kautta.

Artikkeli julkaistiin uudelleen nimenomaan identiteettejä käsittelevässä kirjassa: Rajchmanin kokoelma Question of Identity (Laclau 1995) oli ajalleen tyypillinen. Vaikka Laclau ja Mouffe on yhdistetty identiteettipolitiikkaan, heidän väitteensä on pikemminkin päinvastainen. Kuten Pirkkoliisa Ahponen $(2008,138)$ kirjoitti "identiteettipolitiikka merkitsee sosiaalisia tasa-arvomäärittelyjä purkavaa erojen politiikkaa". Erityisyysargumentti luo toisille etua toisten yli, kun taas muun muassa Mouffe (1993) pyrki 1990-luvulla korostamaan erityisten välistä tasa-arvoa poliittisena prosessina. Laclau kritisoi tässä käännetyssä artikkelissaan hieman identiteettipolitiikan subjektiposition käsitettä, koska se on selkeärajainen ja tiettyyn sijaintiin, kontekstiin tai tilanteeseen liittyväinen. Näin ollen sitä kannattaa varoa essentialisoimasta tai näkemästä yhtenä.

Laclau korostaa, että liberaalin demokratian homogeenisemmille yhteisöille luodut instituutiot ja demokratiateoria on dekonstruoitava, viitaten liberalismille tyypilliseen universalismiin. Universalismille vastapainona tarjottu ääripartikularismi - kuten vaikkapa etno-nationalismi - ei kuitenkaan tarjoa vaihtoehtoa, vaan poliittisen umpikujan. Analogisesti voimme nykyään puhua liberaalin ja illiberaalin demokratian välisestä kamppailusta. Erityinen ottaa aina hetkellisesti universaalin paikan ja vaikkapa käyttää valtaa hallituksena, mutta demokratialle välttämätön avoimuus turvataan sillä, että yleisen ja erityisen välinen ristiriita tuodaan näkyväksi. Kyse on myös siitä, miten "me" määritellään toisen läsnäolon kautta. Oppositiolla on oltava riittävästi tilaa sekä haastaa hallitus että luoda uusia jakolinjoja. Polarisoituminen hallitus-oppositioon mahdollista, mutta tällainen kehitys tuottaa samankaltaisia ongelmia.

Universalismi viittaa hegemoniaan ja hegemonianteoriaan, josta Laclau ja Mouffe olivat jo kirjoittaneet 1980-luvulla (Laclau ja Mouffe 1985): merkityksenannon kenttä on taistelun kenttä. Laclau ja Mouffe ammentavat myös Louis Althusserin teoriasta, joka on taas irtiotto gramscilaisesta traditiosta. Althusser teoretisoi ideologiaa pikemminkin kuin ideologioita, ja ideologian materiaalisuutta ja sen elämistä käytännöissä sekä sitä kun ideologia kutsuu subjektiksi tulemisen 
kautta (Althusser 1984, 114; ks. myös Lahtinen 1997). Laclau ei missään nimessä tahdo ajatella, että koska merkityksenanto on kontingenttia ja täydellinen poliittinen "me" ei toteudu, poliittista kamppailua ei pitäisi käydä. Päinvastoin. Poliittiselle kamppailulle antagonismi ja vastahegemonia ovat hetkellisesti tarpeellisia, mutta anti-essentialistin on vaikea argumentoida jakolinjan vakiintumisen puolesta - ainakaan teoreettisella tasolla. Myöhemmässä työssään Laclau keskittyi siihen, miten "meidän" muodostaminen tapahtuu? Tämän artikkelin kuvaama logiikka luotaa sitä: Jokaiseen samaistumisen hetkeen liittyy myös erottautuminen. Myös väite siitä, että ei ole olemassa "meitä", sisältää uuden identifioinnin pisteen ja position "meidän" luomiseen. Sen sijaan, että moralisoisimme tätä meidän tuottamista, kuten Laclaun kriitikot (vrt. Müller 2017; Arditi 2010), ajatellaanpa, että "me"-samaistuminen todella on keskeinen politiikan logiikka, hyvässä ja pahassa. Identiteetti on pirullinen käsite, mutta politiikka syntyy samaistumisista.

Jokaiseen samaistumisen hetkeen kuitenkin liittyy myös erottautuminen. Esimerkiksi ajankohtainen Yhdysvalloista liikkeelle lähtenyt rasisminvastainen liikehdintä Black Lives Matter havainnollistaa tätä nostamalla esiin sen, että amerikkalaisissa on yksi joukko, joka kokee systemaattista syrjintää (Alexander 2012). Tämä tekee kaikista ryhmään kuuluvista amerikkalaisista samanarvoisia, vaikka heidänkin välillään on eroja. Kaikkia ei syrjitä samalla tavoin ja toisia syrjitään jopa enemmän. Samoin Yhdysvalloissa on muitakin syrjittyjä ryhmiä: tämä partikulaarin universalisointi sorron symboliksi tehokkaasti sekä piilottaa moninaisuuden että voi myös nostaa myös muita ristiriitoja.

\section{LACLAU TEORIASTA AMMENTAVA ESSEXIN KOULUKUNTA PARTIKULAARINA UNIVERSAALINA}

Nyt suomennettu artikkeli on yksi keskeisiä diskurssiteorian artikkeleja niin teoreettisesti kuin menetelmällisesti. Laclaun ajattelusta ammentavalle lähestymistavalle on kertynyt nimiä ja sovelluksia vuosien kuluessa: laclaulainen diskurssiteoria on kuvattu menetelmänä 1980-luvulta ideologia- ja diskurssianalyysinä (IDA). Sillä on myös muita nimikkeitä ja etuliitteitä, kuten poliittinen, jälkistrukturalistinen (Howarth ym. 2000; Howarth 2014) tai jälkiperustahakuinen (post-foundational) diskurssiteoria (vrt. Marttila 2019). Tässä käytän yleiskäsitettä diskurssiteoria vaikka tälläkin käsitteellä on muita viittauskohtia. Metodisesti laclaulainen lähestymistapa voidaan liittää tulkitsevaan politiikan tutkimukseen tai politiikka-analyysiin (Finlayson 2007; ks. myös Häikiö ja Leino 2014). Diskurssiteorialla voi myös selittää politiikan ilmiöitä: arkipäiväisesti sanottuna diskurssiteoria etsii vastausta kysymykseen "mistä on kyse" tunnistaen erilaisia logiikoita tätä merkityksenannon prosessia kuvaamaan tai selittämään.

Sukupolvina voidaan tunnistaa 1980-90-lukujen vahva ideologia- ja diskurssianalyysin kausi, jolloin kehitettiin ja sovellettiin Laclaun teorian peruskäsitteitä: tälle tyypillistä on subjektipositioiden ja diskurssien sekä siirtymien tunnistaminen erilaisissa kamppailuissa. Seuraava sukupolvi Essexin yliopiston menetelmiin keskittyneellä ja kilpailuhenkisellä laitoksella sai kylmää kyytiä eklektisestä lähestymistavastaan. Kritiikissä nousi esiin analyysin historiattomuus, välinpitämättömyys systemaattisesta menetelmällisyydestä ja aineistonkeruusta sekä analyysitekniikoiden auki kirjoittamisesta. Toinen sukupolvi 2000-luvulla alkoi metodisuuden paineen alla rinnastaa essexiläisen analyysin muihin menetelmiin ja erityisesti tulkitsevan analyysin 
laajempaan kehykseen (Howarth ym. 2000; Howarth ja Torfing 2004). Diskurssiteoreetikot tutkivat "hegemonian tuottamista prosessina" (Norval 2000, 227). Voidaan ajatella, että diskurssiteoreetikon tehtävä on tunnistaa merkitysten tuottamisen logiikoita ja prosesseja pikemminkin kuin keskittyä metatason diskursseihin. Glynos ja Howarth (2007) tunnistivat logiikoiden hyödyntämisen ja diskurssiteorian selittävän voiman psykoanalyyttisen teorian ja kriittisen realismin avulla.

Uusi polvi tuo esiin kuinka diskurssiteoria keskittyy käytäntöihin ja materiaalisuuteen poliittisesta taloudesta aina vallan kabinetteihin ja yhteiskunnallisiin liikkeisiin, työpaikoille ja rakennettuun ympäristöön (Marttila 2019). Tämä haastaa väitteen siitä, että Laclau ja Mouffe keskittyvät enemmän diskurssiin, kieleen tai puheeseen (Neumann 2002, 629-630). Diskurssi voi olla myös visuaalisuutta ja sitä kautta hyvinkin materiaalista (esim. Salojärvi 2019). Juuri toiminta on merkitysten perustamista ja kiinnittämistä. Laclaun anti- tai pikemminkin jälkiperustahakuinen (Marchart 2007) ja anti-essentialistinen lähestymistapa olettaa, että merkitykset eivät ole ennalta annettuja, vaan ne luodaan artikulaation kautta (Hall 1999). Rakenteiden, konstruktioiden ja rakentamisen sijaan voidaan puhua artikulaation perustavasta ja muokkaavasta luonteesta. Myöhemmin myös retoriikkaa korostava tulkinta alkoi nousta esiin sekä luotiin kontakteja mm. Michael Freedeniin ja Quentin Skinneriin (ks. Howarth 2014).

\section{KLASSISTEN ARTIKKELIEN UUDELLEEN JULKAISUSTA}

Laclau ei koskaan julkaissut runsaasti eikä varmasti riittävästi niihin vaatimuksiin nähden, joita Essexissä jo 2000-luvun alussa yliopistomaailman uusliberaalisoituessa esitettiin. Nyt suomennettu artikkeli julkaistiin myös klassisessa kokoelmassa Emancipation(s) (Laclau 1996), jota tästä artikkelista pitäville suosittelen. Laclaun viimeiseksi teokseksi jäi kokoelma artikkeleja yhteiskunnan retorisesta perustasta (Laclau 2014).

Artikkelien uudelleenjulkaiseminen kertoo niiden merkityksestä. Globaalin akateemisen kapitalismin kulta-aikana - jolloin tieteellinen teksti on merkityksellinen, koska se ylläpitää kustantajia ja rahoittaa heidän sijoittajiaan - unohtuu, että tieteessä laatu korvaa määrän. Yksi hyvä artikkeli on ehkä kuitenkin parempi kuin pussillinen keskinkertaisia. Monet laclaulaiset kollegani yhä käyttävät nyt käännettyä ja julkaistua artikkelia edelleen jatkuvasti opiskelijoidensa kanssa. Toivottavasti teimme käännöksellämme tekstille oikeutta ja se herättää keskustelua myös suomeksi. Toisin kuin usein tunnutaan ajateltavan, tieteellisen artikkelin tehtävä ei ole meritoida tutkijaa tai kerätä rahaa yliopistoille - tai yliopistoilta, eli Suomessa veronmaksajilta, supervoittoja tavoitteleville kustantajille. Artikkelin tehtävä on tulla luetuksi ja luoda yhteisöä, joka saa jotain irti artikkelista. Teksti tarjoaa samaistumispintaa - jopa yhteyttä erillisen ja yleisen välillä.

Kirjoittaja on Ernesto Laclaun entinen oppilas, joka teki maisterintutkintonnon ja väitöskirjan Essexin yliopistossa vuosina 2000-2006 Aletta Norvalin ohjauksessa. Hän on opettanut useammalle sukupolvelle ideologia- ja diskurssiteoriaa myös Suomessa - vuodesta 2006 Helsingin yliopistossa, mutta joinain vuosina myös Helsingin seudun kesäyliopistossa ja Lapin ja Jyväskylän yliopistoissa. 


\section{LÄHTEET}

Ahponen, Pirkkoliisa. 2008. Tasa-arvoa vai erojen politiikkaa? Sosiaalisesta kulttuuriseen kansalaisuuteen. Janus Sosiaalipolitiikan ja sosiaalityön Tutkimuksen Aikakauslehti 16:2 127-145. https://journal. fi/janus/article/view/50464.

Althusser, Louis. 1984. Ideologiset valtiokoneistot. Helsinki, Tampere: Kansankulttuuri \& Vastapaino.

Alexander, Michelle. 2012. The New Jim Crow: Mass Incarceration in the Age of Colourblindness. New York: The New Press.

Arditi, Benjamin. 2010. Review essay: populism is hegemony is politics? On Ernesto Laclau's on populist reason. Constellations 17(3), 488-497. https://doi.org/10.1111/j.1467-8675.2010.00587.x

Finlayson, Alan. 2007. From beliefs to arguments: Interpretive methodology and rhetorical political analysis. The British Journal of Politics and International Relations 9:4, 545-563.

https://doi.org/10.1111/j.1467-856x.2007.00269.x

Hall, Stuart. 1999. Identiteetti. Tampere: Vastapaino.

Howarth, David. 2000. Discourse, Buckingham ja Philadelphia: Open University Press.

Howarth, David, Norval, Aletta ja Stavrakakis, Yannis (toim.) 2000. Discourse Theory and Political Analysis: identities, hegemonies and social change. Manchester: Manchester University.

Howarth, David (toim.) 2014. Ernesto Laclau: post-Marxism, populism and critique. Lontoo \& New York: Routledge.

Häikiö, Liisa ja Leino, Helena (toim.). 2014. Tulkinnan mahti: johdatus tulkitsevaan politiikka-analyysiin. Tampere: Tampere University Press. http://urn.fi/URN:ISBN:978-951-44-9560-1.

Laclau, Ernesto. 1992. "Universalism, Particularism and the Question of Identity." October 61, 83-90.

Laclau, Ernesto, 1995, "Universalism, Particularism and the Question of Identity." Teoksessa John Rajchman (toim.), The Identity in Question. New York ja Lontoo: Routledge.

Laclau, Ernesto. 1996. Emancipation(s). Lontoo: Verso.

Laclau, Ernesto. 2005. On Populist Reason. Lontoo: Verso.

Laclau, Ernesto. 2014. The Rhetorical Foundations of Society. Lontoo: Verso.

Laclau, Ernesto ja Mouffe, Chantal. 1985. Hegemony and Socialist Strategy. Lontoo: Verso.

Lahtinen, Mikko. 1997. Niccolò Machiavelli ja aleatorinen materialismi: Louis Althusser ja Machiavellin konjunktuurit. Tampere: Tampereen yliopisto.

Marchart, Oliver. 2007. Post-Foundational Political Thought: Political Difference in Nancy, Lefort, Badiou and Laclau. Edinburgh: Edinburgh University Press.

Marttila, Tomas. 2019. Discourse, Culture and Organization: Inquiries into Relational Structures of Power. Cham: Palgrave Macmillan.

Mouffe, Chantal. 1993. Return of the Political. Lontoo: Verso.

Müller, Jan-Werner. 2017. Mitä on populismi? Tampere: niin \& näin.

Neumann, Iver B. 2002. Returning Practice to the Linguistic Turn: The Case of Diplomacy. Millennium Journal of International Studies 31:3, 627-651. https://doi.org/10.1177/03058298020310031201.

Palonen, Emilia. 2008 Ernesto Laclau \& Chantal Mouffe: diskurssiteoriaa ja radikaalia demokratiaa. Teoksessa Kia Lindroos ja Suvi Soininen (toim.), Politiikan nykyteoreetikkoja. Gaudeamus, 209-232.

Salojärvi, Virpi. 2019. Populism in Journalistic Photographs: Political Leaders in Venezuelan Newspaper Images. Iberoamericana; Nordic Journal of Latin American and Caribbean Studies 48:1, 28-39. https://doi.org/10.16993/iberoamericana.439. 


\section{KIRJOITTAJATIEDOT}

\section{EMILIA PALONEN}

PhD, yliopistonlehtori

Yleinen valtio-oppi

Valtiotieteellinen tiedekunta

Helsingin yliopisto

emilia.palonen@helsinki.fi 